ISSN: 2448-0657

periodicos.ufsm.br/refilo

Universidade Federal de Santa Maria/UFSM Santa Maria, RS, Brasil

\title{
CAMINHOS LITERÁRIOS DO ENSINO DE FILOSOFIA
}

\author{
LITERARY PATHS OF PHILOSOPHY TEACHING
}

\begin{abstract}
Álvaro de Souza Maiotti
Resumo: $O$ objetivo do presente artigo consiste em delinear uma proposta metodológica para o ensino de filosofia fundamentada em suas relações com a literatura. Como ponto de partida, adotamos uma concepção contemporânea e bem específica quanto à natureza da filosofia e de seu ensino, na qual seu desenvolvimento é provocado pelos problemas que são explorados e discutidos pelos filósofos ao longo da história. Dentre as metodologias disponíveis, a abordagem problemática do ensino de filosofia mostra-se a mais coerente com a natureza da disciplina e de seu ensino, porque postula o exercício criativo do filosofar por parte do estudante. Considerando algumas pedagogias atuais que postulam uma forma de ensino menos compartimentada e mais integrada, sua articulação com a literatura apresenta-se como um caminho possível para o ensino de filosofia no contexto da educação básica. Dadas as antigas relações entre filosofia e literatura, texto e discurso surgem, há um tempo, como recurso e produto das aulas.
\end{abstract}

Palavras-chave: Educação Básica; Ensino de Filosofia; Literatura.

Abstract: The aim of this paper is to outline a methodological proposal for the teaching of philosophy based on its relations with literature. As a starting point, we adopt a contemporary and very specific conception of the nature of philosophy and its teaching, according to which its actualization is brought about by the problems explored and discussed by the philosophers through the history. Among the available methodologies, the problematic approach of philosophy teaching is shown to be more coherent with the nature of the discipline and its teaching because it posits the student's creative exercise of philosophizing. Taking into consideration some current pedagogies that postulate a less compartmentalized and more integrated way of teaching philosophy, its articulation with de literature presents itself as a possible way for teaching philosophy in the context of basic education. Given the long established relations between philosophy and literature, text and speech come out as resource and product of the lessons in the classroom at the same time.

Keywords: Basic Education; Literature; Philosophy Teaching.

E-mail: alvaro_maiotti@yahoo.com.br 


\section{INTRODUÇÃO}

A história da filosofia no Brasil nos mostra que sua presença na educação básica não se consolidou sem conflitos de ordem política e ideológica. Acompanhando, ao longo dos anos, a exclusão e o reingresso da disciplina nos currículos do ensino médio, diversos pensadores dedicaram-se e continuam se dedicando à elaboração de propostas metodológicas que viabilizem seu ensino.

É neste cenário que o presente trabalho se insere, objetivando responder ao seguinte problema: de que forma as relações entre filosofia e literatura podem possibilitar a elaboração de uma proposta metodológica para o ensino de filosofia no contexto do ensino médio? Partindo de uma concepção contemporânea em relação à natureza da filosofia e de seu ensino, na qual seu desenvolvimento é provocado pelos problemas que são explorados e discutidos pelos filósofos ao longo da história, este estudo perpassa suas principais abordagens metodológicas adotando, finalmente, a que se mostra mais coerente e profícua e que nos permite a relação entre esses dois campos do saber. De modo que se constitui como um estudo eminentemente teórico, os métodos da pesquisa bibliográfica foram empregados à sua realização.

Dentre as muitas razões que justificam a sua realização, pode-se destacar ao menos a estreita relação entre filosofia e literatura que, segundo Heuser (2016), é visível ao menos desde Aristóteles:

Ao menos desde Aristóteles, fundador do Liceu, ou do Perípato, (335/334 a.C.), é que a Filosofia está ligada à leitura. Desde sua época de estudante, Aristóteles foi chamado de "O Leitor", gastou fortunas em obras advindas de distintos lugares, que versavam sobre os mais variados temas. [...] Estima-se que o acervo da biblioteca deixada por Aristóteles, no Liceu, era composto de cerca de 10.000 papiros, sendo que, de autoria de Aristóteles eram mais de 382 obras, contidas em mais de 1005 rolos de papiro, além de outros originais ou cópias de autores da escola peripatética (colegas de Aristóteles que trabalhavam no Liceu) e papiros de escritores antigos ou contemporâneos ao filósofo. (HEUSER, 2016, p. 9).

Além do interesse investigativo da filosofia pela literatura - que se evidencia em pesquisas da área de estética, por exemplo - essa íntima relação entre ambas lhe permitiu, em última análise, a sobrevivência e permanência ao longo da história. Afinal, sem os registros escritos, dificilmente teríamos acesso ao que os filósofos exploraram e discutiram ao longo de tantos anos.

\section{NATUREZA DA FILOSOFIA E DE SEU ENSINO}

Qualquer tipo de metodologia de ensino precisa levar em consideração a natureza da disciplina à qual pretende se ajustar. Afinal, cada disciplina possui um modus operandi: um discurso próprio, regras próprias de atuação e de estudo de seus objetos, objetivos específicos a serem atingidos, entre outros. Em se tratando de filosofia, a definição de sua natureza torna-se um problema interessante visto que, quanto a isso, não há consenso entre os filósofos: "[...] O que é a filosofia? Esta é uma pergunta polêmica. De alguma forma, cada filósofo a responde de maneira diferente, pelo menos quando esse filósofo instaura uma tradição. Assim, as escolas ou tradições de pensamento inauguram um modo de entender a filosofia [...]". (GUIDO; GALLO; KOHAN, 2013, p. 104). 
Numa palestra ${ }^{2}$ aos professores de filosofia da zona sul da cidade de São Paulo, o Prof. Dr. Silvio Gallo destacou a importância da adoção de uma concepção de filosofia como ponto de partida para a escolha de estratégias metodológicas que viabilizem seu ensino, advertindo que o que se entende por filosofia interfere diretamente no modo como ela será ensinada e nos objetivos que este ensino deverá alcançar. Diante da profusão de concepções, adotou-se como ponto de partida uma definição contemporânea que, a nosso ver, abarca aspectos que são comuns a todas as concepções de filosofia, tornando-se útil à elaboração de uma estratégia metodológica condizente com o cenário do ensino médio e com os tempos atuais.

Para definir a natureza da filosofia, Murcho (2002) a compara com a natureza das demais áreas de conhecimento e conclui que ela difere das outras apenas em grau, e não em espécie. $O$ que as aproxima é o fato de não estarem completamente acabadas, mas em contínuo processo de formação. Todavia, ao contrário das demais áreas que já possuem certa quantidade de conteúdos nos quais podem-se apoiar na busca pela transposição das fronteiras/limites do conhecimento, não se sabe praticamente nada a respeito da filosofia, uma vez que ela se desenvolveu a partir do confronto de ideias dos filósofos que, ao longo de tantos anos de estudo, se dedicaram à exploração de problemas e à discussão de suas soluções.

Embora não possa se apoiar numa imensidão de conhecimentos filosóficos, o filósofo pode e deve valer-se dos mesmos conhecimentos produzidos pelas demais áreas, em função do que pretende investigar: afinal, não é possível resolver problemas da área de estética sem ter conhecimentos acerca de arte, por exemplo. Esse aparato, contudo, ainda é insuficiente para a resolução dos complexos problemas das fronteiras de conhecimento da filosofia. (MURCHO, 2002).

Diante da perplexidade e desorientação provocadas por sua natureza, surge a tentação de por fim à filosofia, de transformá-la em algo que seja mais facilmente definível ou de lhe atribuir funções que originariamente não the pertencem (MURCHO, 2002): é o que se pode ver no Currículo de Ciências Humanas e suas tecnologias, produzido pela Secretaria da Educação do Estado de São Paulo para ser implantado em todas as escolas paulistas da rede pública de educação. De acordo com este documento, "[...] os 'conhecimentos filosóficos' foram reconhecidos pela própria Lei de Diretrizes e Bases da Educação Nacional (LDBEN) como fundamentais ao exercício da cidadania". (SÃO PAULO, 2010, p. 114). Atribuir à filosofia ou aos professores de filosofia a incumbência de ministrar aos jovens do ensino médio conteúdos que lhes permitam o exercício da cidadania, significa instrumentalizar a disciplina para o alcance de metas que lhes são naturalmente estranhas. Nas palavras de Gallo (2012):

[...] desde Aristóteles a filosofia se define como um fim em si mesmo, e não como um meio para atingir um objetivo determinado. Justificar um espaço para a filosofia nos currículos da educação básica apenas de modo instrumental - isto é, a filosofia a serviço de algo, como a cidadania - é, portanto, essencialmente antifilosófico. (GALLO, 2012, p. 21).

Outra tentação, segundo Murcho (2002), é transformar o ensino de filosofia em ensino de história da filosofia, substituindo a discussão dos problemas filosóficos pelo ensino da história dessa discussão - o que novamente evidencia a desorientação quanto à sua natureza:

[...] reduzir a Filosofia a outras disciplinas é sintoma de que andamos desesperados à procura de conteúdos, queremos que a Filosofia

2 Orientação Técnica promovida pela Diretoria de Ensino - Região Sul 1, dirigida aos professores de filosofia de sua jurisdição e realizada nas dependências da Biblioteca Municipal Belmonte - Santo Amaro, zona sul de São Paulo, no dia 9 de agosto de 2017. 
tenha conteúdos, como a Física ou a Musicologia. Ou acabamos por fazer da história da Filosofia o próprio conteúdo da Filosofia. Em ambos os casos há desorientação e uma incompreensão de base da natureza da Filosofia. (MURCHO, 2002, p. 15).

Se não há conteúdos a serem ensinados, os problemas da filosofia passam a ser o foco de estudo e de ensino dessa disciplina. Para tanto, é necessário possuir conhecimentos relevantes de outras áreas, além de conhecer, minimamente, o momento atual de discussão desses problemas. Também é necessário saber discutir problemas, fazendo uso das lógicas formal e informal.. Deve-se partir de problemas mais simples e avançar, gradualmente, para os mais difíceis, considerando a compreensão dos filósofos e suas distintas teorias para resolvê-los; contrastando suas formas de compreensão com a nossa própria, de modo a enriquecê-la, traçando distinções e corrigindo confusões: um processo que envolve análise e comparação de múltiplas teorias e a formulação da própria opinião ou teoria (MURCHO, 2002).

Teorias filosóficas, segundo Murcho (2002), apoiam-se quase que exclusivamente em argumentos filosóficos. Diferentemente de outras disciplinas, a filosofia não dispõe de métodos formais de prova, testes empíricos e laboratoriais ou dados estatísticos; e nem se apoia em raciocínios matemáticos e formais: o que ela tem à disposição é o resultado das outras ciências e sua capacidade de refletir, de forma rigorosa e detalhada, sobre os problemas que lhe interessam — de onde advém a importância de se conhecer os mecanismos das lógicas formal e informal para evitar confusões e falácias. Por essas razões, a correta compreensão da natureza da filosofia

[...] obriga a que o seu ensino procure o seguinte: o estudante terá de compreender claramente os problemas, as teorias e os argumentos da filosofia e terá de formar a sua opinião abalizada sobre eles; o estudante deverá ser estimulado a desenvolver o seu pensamento autônomo sobre os problemas, as teorias e os argumentos da Filosofia. Terá de ser capaz de traçar distinções relevantes, de saber defender as suas idéias, de conhecer os argumentos que se levantam contra as suas idéias e de saber responder-lhes de forma adequada e responsável. Terá de conhecer as alternativas às idéias que defende, e terá de saber explicar por que razão as idéias que defende são melhores do que as alternativas. Terá de saber argumentar sem cair em falácias, terá de ser capaz de reagir a contra-argumentos e a contra-exemplos, terá de dominar os pormenores técnicos e as sutilezas das teorias e argumentos mais complexos. (MURCHO, 2002, p. 16).

Como se pode observar, o espaço para discussão de ideias é um dos elementos mais fundamentais de uma prática de ensino de filosofia de qualidade. Para Murcho (2002), essa prática de ensino também se desenvolve em outros momentos igualmente importantes como, por exemplo, o de exposição, por parte do professor, dos problemas, teorias e argumentos da filosofia; ou o de realização de exercícios de redação de pequenos ensaios expositivos onde o estudante formula um problema, uma teoria ou um argumento sem necessariamente os discutir — mas, em geral, pede-se aos estudantes ensaios mistos. A realização desses exercícios os conduz a uma autoavaliação rigorosa que tem por primeiro efeito o abandono dos próprios erros: 
precisamente porque está a refutar o que ninguém defende; se formular mal um problema, a sua solução será uma tolice, porque poderá estar baseada numa confusão. Esse método de misturar as coisas é conforme à natureza humana e à natureza da própria Filosofia: é muito difícil estudar um determinado problema, teoria ou argumento e não começar imediatamente a ter idéias sobre tudo aquilo. Nesse tipo de ensino, estimula-se isso, mas mostra-se que nem todas as idéias que temos são boas. Na verdade, o estudante rapidamente percebe que a esmagadora maioria das idéias que temos não vale nada - mas temos de começar por algum lado e o melhor é começar pelos nossos erros, pois, quanto mais cedo nos livrarmos deles, melhor. (MURCHO, 2002, p. 17).

Abandonar os próprios erros conceituais e de argumentação é apenas o primeiro dos muitos efeitos positivos que um ensino de filosofia de qualidade pode promover. Como bem destaca Murcho (2002):

[...] o estudante sai da disciplina sabendo pensar com mais clareza, sabendo traçar distinções, sabendo detectar e evitar erros de raciocínio, sabendo avaliar opiniões opostas e a tomar decisões informadas e refletidas. Como é evidente, isso é de importância fundamental para a vida pública e cultural de qualquer sociedade. (MURCHO, 2002, p. 15).

Uma breve análise da natureza da filosofia e de seu ensino nos impele, portanto, para uma prática de ensino que aponta para um exercício ativo e criativo de produção de filosofia, exercício esse que envolve a formação de opinião, o desenvolvimento de pensamento autônomo, a defesa das próprias ideias, o conhecimento de técnicas de argumentação - habilidades essenciais à formação de qualquer cidadão. É curioso notar que, quando estes objetivos são impostos à disciplina de maneira arbitrária, corre-se o risco de não ensinarmos filosofia e de não contribuirmos com a formação de cidadãos críticos e autônomos.

\section{PRINCIPAIS ABORDAGENS METODOLÓGICAS}

Conforme Guido, Gallo e Kohan (2013) algumas possibilidades metodológicas foram propostas com o intuito de atingir os propósitos acima mencionados e promover um ensino de filosofia de qualidade. Dentre elas, destacam-se a abordagem histórica, o enfoque temático e o ensino por problemas. Em termos de organização curricular há, portanto, ao menos três eixos em torno dos quais pode-se construir um currículo de filosofia: um eixo histórico, um eixo temático e um eixo problemático.

Como o próprio nome sugere, a abordagem que parte do eixo histórico prioriza o ensino da história da filosofia, uma vez que os conteúdos são organizados a partir de uma cronologia histórica. Durante a implantação da disciplina nas universidades brasileiras, a partir de 1934, a nomenclatura história da filosofia passou a designar um modo de leitura dos textos clássicos apresentado por Victor Goldschmidt, constituindo-se em um método para o estudo filosófico. Esse modelo, contudo, restringia a prática do pensamento ao texto, à apreensão da estrutura da obra, restando apenas a possibilidade de compreensão dos sistemas filosóficos e de extração de suas verdades formais. Segundo Benoit (2013), para Goldschmidt a filosofia é discurso, palavra escrita, lexis, explicitação. Assim, "Só importa ao intérprete o que está plenamente desenvolvido, ou seja, o texto 
em sua forma acabada. Não interessa ao intérprete a busca do que está por trás do texto, não interessa saber se alguma consciência, intuição, sujeito etc. o produziu". (BENOIT, 2013, p. 133, grifo da autora). Como foi possível observar, seu grande problema é o risco que se corre de se cair num ensino enciclopédico. A principal crítica dirigida a ele, portanto, é a ênfase que se dá ao conteúdo em detrimento do exercício do pensar enquanto atividade (GUIDO; GALLO; KOHAN, 2013).

Mediante a abordagem temática elegem-se conteúdos de natureza filosófica, que podem ou não ser tratados com uma perspectiva histórica, numa tentativa de aproximá-los da realidade vivida pelos jovens. Este tipo de organização curricular está presente em alguns dos principais manuais didáticos para o ensino médio produzidos a partir dos anos 1980 e em documentos oficiais - como o já citado Currículo de Ciências Humanas e suas tecnologias, do Estado de São Paulo. Sua principal justificativa reside na possibilidade de uma abordagem mais bem contextualizada dos conteúdos filosóficos, além das inúmeras possibilidades didáticas de trabalho do professor. Entretanto, a mesma crítica endereçada à abordagem histórica pode lhe ser dirigida na medida em que ela também poderia se reduzir a uma transmissão de conteúdos filosóficos (GUIDO; GALLO; KOHAN, 2013).

A abordagem problemática, por sua vez, propõe uma organização dos conteúdos que possibilite a explicitação dos problemas que mobilizaram o pensamento e a construção de conceitos pelos filósofos, conforme seu movimento de criação. Apoia-se, portanto, fundamentalmente, na concepção deleuziana de problema3 enquanto força motriz do pensamento filosófico. Os problemas podem ser relacionados ainda a outros dois conceitos elaborados pelo filósofo. Eles pertencem à ordem do acontecimento - algo caótico e imprevisível, portanto (GUIDO; GALLO; KOHAN, 2013). Como bem esclarece Gallina (2004):

Os problemas filosóficos não se encontram nos textos dos filósofos e sequer podem ser comunicados pelos professores de filosofia; eles estão submetidos aos devires, às orientações e às direções que não pertencem à história da filosofia, mas do acontecimento. Mesmo que os problemas estejam orientados para o passado ou para o futuro, eles estão submetidos às multiplicidades, aos devires que emergem como forças que operam em silêncio. Os problemas emergem dos acontecimentos e das experimentações. (GALLINA, 2004, p. 361, grifo da autora).

O problema também é sempre uma singularidade composta por um agenciamento de singularidades. Ele nos move a pensar porque, enquanto singularidade, não apresenta uma fórmula pré-determinada: ele se apresenta para nós como um desafio para o qual precisamos construir uma resposta. A resolução do problema depende dos agenciamentos das singularidades que o compõem (GUIDO; GALLO; KOHAN, 2013). E isso define, em certo sentido, a atividade de um filósofo:

A atividade de criação do filósofo é um agenciamento que garante um registro único, singular, perante a tradição filosófica. A capacidade para constituir ou inventar problemas, cuja solução depende da multiplicidade de relações, das singularidades e, sobretudo, depende da determinação das condições do próprio problema, é a capacidade que torna possível o surgimento do filósofo. (GALLINA, 2004, p. 367, grifo da autora).

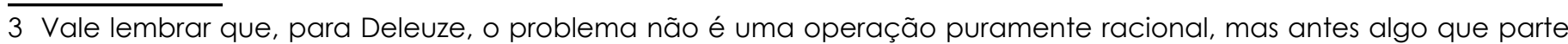
do que é sensivel: a experiência problemática é primeiramente vivenciada antes de ser equacionada racionalmente como problema. 
Guido, Gallo e Kohan (2013) destacam que o problema não pode ser utilizado como um artifício para a construção do pensamento; não pode ser empregado como metodologia, como etapa a ser superada no processo de construção do conhecimento filosófico. Para que seja agenciador de experiências no pensamento ele deve ser objetivo: vivenciá-lo sensivelmente torna-se mais importante do que sua resolução. Isso nos conduz para a autonomia do pensamento que se realiza nessa experiência particular, real e criativa e que é possibilitada pela chamada pedagogia do problema, ainda a ser inventada. A esta nova pedagogia caberia, portanto "[...] o estabelecimento do problemático, a invenção de experimentações que levassem cada um a experimentar seus problemas e, a partir deles, 'engendrar pensar no pensamento'". (GUIDO; GALLO; KOHAN, 2013, p. 123). Ao tratar deste "pensar" que é engendrado no próprio pensamento e que se instaura a partir do enfrentamento de problemas reais, Deleuze fala em criar conceitos. Isso nos permite concluir que: "Experimentar problemas em filosofia significa, portanto, mobilizar o pensamento para criar conceitos como enfrentamento a tais problemas". (GUIDO; GALLO; KOHAN, 2013, p. 125).

Em linhas gerais, observa-se que as concepções da natureza da filosofia e de seu ensino apresentadas por Murcho (2002) vão ao encontro do que é proposto por Deleuze e que nos é apresentado por Guido, Gallo e Kohan (2013): o problema e sua experiência concreta - força motriz do pensamento - emergem como matéria-prima de uma prática autêntica e qualitativa de ensino de filosofia. E essa prática resultará no fazer filosófico por parte dos estudantes: um processo criativo de produção de ideias, de produção de filosofia, que se materializa nos conceitos que são criados para o enfrentamento dos problemas experienciados, vividos concretamente.

\section{FILOSOFIA E LITERATURA}

Se para Heuser (2016), como vimos, a relação entre filosofia e literatura é visível ao menos desde Aristóteles, e esteve evidenciada pelo interesse e gosto do filósofo pela leitura — fato atestado pela extensão de seu acervo pessoal. Para Gagnebin (2016), é antes a própria constituição histórica e linguística da filosofia que torna possível esse tipo de relação:

Quando digo "constituição histórica e linguística", digo duas coisas simples, mas que muitas vezes esquecemos: a primeira, que a filosofia se autodefine e é definida de diversas maneiras segundo os momentos de sua história, segundo os momentos da história: na Idade Média, tinha que se confrontar principalmente com a teologia, por exemplo, na modernidade, desde Descartes, com as matemáticas e com as ciências exatas, hoje com outras ciências ditas humanas ou naturais; a segunda coisa é que a filosofia só pode se dar na e pela linguagem [...]. História e Linguagem, inseparáveis, delimitam o exercício filosófico, fazendo sua grandeza e sua fragilidade - e tecendo seu parentesco com aquilo que, a partir do Romantismo alemão, costumamos chamar de "literatura". (GAGNEBIN, 2016, p. 5, grifo da autora).

Gagnebin (2016) observa que as aproximações filosóficas vigentes buscam tratar os textos literários como recursos ilustrativos dos conceitos filosóficos: é como se existisse, sob os conceitos filosóficos, uma verdade mais "profunda" que, dita apenas de modo indireto pelo escritor, é anunciada de maneira clara e explícita pelo filósofo. Uma postura que revela uma visão preconceituosa em relação à literatura e à filosofia uma vez que a primeira é vista como um discurso ornamental - da imagem ou metáfora - ao passo que a segunda é vista como um discurso 
objetivo e verdadeiro do conceito. Essa dicotomia entre sensível e inteligível, contudo, deve ser analisada e superada.

Para Gagnebin (2016), a introdução desta oposição na reflexão deve-se à filosofia platônica, ainda que seu autor não a tenha estabelecido de modo tão radical como se costuma dizer . A desconfiança de Platão em relação à poesia e à retórica, sua tentativa de distinguir de maneira clara o discurso dos Sofistas e o de Sócrates - ao qual ele denomina como filosofia e reivindica para si em sua prática de mestre e de escritor - não nascem, portanto, de uma condenação do sensível enquanto tal, mas de sua possibilidade de autossustentação e autossuficiência:

[...] porque ele sabe o quanto gosta de teatro, poderíamos dizer, Platão fareja ali o perigo maior: que a sedução da beleza tenha mais força que a procura, muitas vezes difícil, ingrata, aporética, do verdadeiro. Esse perigo se concretiza nas manipulações dos demagogos (literalmente: aqueles que querem agradar ao povo em vez de educá-lo) na assembleia decisória da cidade e no ensino dos Sofistas que, segundo Platão/Sócrates, ajuda a solapar as antigas virtudes cívicas por argumentos retóricos tão brilhantes quanto vazios. (GAGNEBIN, 2016, p. 7, grifo da autora).

Conforme Gagnebin (2016), o poder emocional e evocativo da mímesis artística chama a atenção porque indica que a imagem comove mais do que a realidade, introduzindo assim, na ontologia, o espaço indefinível da ilusão sedutora. É esse estatuto enganador que funda a assim chamada "condenação da escrita" por Platão. Por meio da narração de um mito, o filósofo nos alerta para o duplo caráter enganador do texto escrito: a princípio parece um remédio para o esquecimento quando, no fundo, é um veneno para a memória. Essa força ambígua caracteriza, já antes de Platão, o canto poético que simultaneamente nos recorda o passado e nos faz esquecer a dor do presente. Há que se observar, também, que o texto escrito se assemelha à pintura e, portanto, embora esteja morto, consiste apenas numa bela imitação da vida. Em síntese poder-se-ia dizer que "[...] a raiz da literatura é a representação da ausência, por metonímia da morte e dos mortos. Não só porque, como no epos antigo, lembra as façanhas dos heróis mortos, mas porque escrever sempre significa abdicar da imediatidade da presença e da palavra viva". (GAGNEBIN, 2016, p. 9, grifo da autora).

Gagnebin (2016) destaca que, nessa mesma perspectiva, Platão desenvolve ainda uma teoria da insuficiência dos signos para apreender o ser em sua essência. Entretanto, ainda que a linguagem seja fraca ou doente, ela não deve ser abandonada. Afinal:

[...] a filosofia consiste em exercícios espirituais incessantes que tem por alvo, não vencer o interlocutor nem chegar a um resultado definitivo, mas depois de muito treino, como depois de friccionar uma pedra contra outra, produzir uma faísca, fazer jorrar uma luz que não pode ser dita, mas que nos consola da fraqueza de nossas palavras. Continuemos, pois, a falar e mesmo a escrever, não tanto apesar das insuficiências da linguagem, mas muito mais em razão delas: na esperança que dessa fragilidade possa surgir como que uma ressonância ou um eco do verdadeiro real. (GAGNEBIN, 2016, p. 10, grifo da autora).

Vemos surgir aqui o tema duplo dos limites da linguagem e do indizível, tema que atravessa toda a nossa tradição filosófica e literária. Em filosofia, os limites da linguagem podem nos conduzir 
tanto a uma filosofia crítica - a de Kant, por exemplo - quanto a uma filosofia contemplativa Platão, Plotino, Santo Agostinho, entre outros. Esse tema é caro, igualmente, para toda a literatura. Os limites da linguagem dizem respeito aos primeiros sentidos do assim chamado indizível, evidenciados em nossa incapacidade de descrição da relação entre nossa linguagem e o mundo: afinal, não é possível nos distanciarmos da linguagem ou do mundo para poder dizer como e se eles se correspondem. Essa relação, rigorosamente, não pode ser dita. Entretanto, a impossibilidade de descrição ou de fala não resulta necessariamente no silêncio (GAGNEBIN, 2016).

O raciocínio desenvolvido até aqui por Gagnebin (2016) nos direciona para uma das principais diferenças entre os domínios circunjacentes da filosofia e da literatura: a primeira, caracterizada por um olhar retrospectivo e examinador, ambiciona conhecer e reconhecer o acontecido sobre o qual se debruça com certa distância - distância própria da reflexão e autorreflexão; já a segunda arriscaria, em oposição a esse olhar que por ela também poderia ser adotado, a dizer daquilo que ainda não aconteceu - seja porque pertence a um futuro desconhecido, seja porque inventa outros mundos, imagina, elabora ficções.

Voltando-se de maneira um pouco mais detida para a literatura, Gagnebin (2016) destaca que sua dimensão ficcional e crítica, observada em seu movimento criativo e inventivo, coloca em questão a metafísica e o senso comum, porque desestabiliza a concepção clássica de verdade como adequação ao real: "[...] Longe de ser um simples divertimento ou uma distração agradável, a literatura, justamente porque é ficção, coloca em questão o real enquanto tal como critério exclusivo de verdade. A literatura nos permite uma ampliação e uma transformação da experiência humana". (GAGNEBIN, 2016, p. 12, grifo da autora). Aí reside a verdade da literatura: nas transformações que ela suscita na percepção da realidade cotidiana. Não dizer o mundo tal como ele é, mas reinventá-lo, é justamente o que possibilita o surgimento desse outro tipo de verdade:

[...] Não se trata, então, de aproximar a ficção do real, mas, pelo contrário de pensar sua distância como o indício de um outro devir que a literatura pode nos fazer pressentir. O retirar-se da arte longe da realidade cotidiana, diz Ricoeur, é também a condição de sua "irrupção" nessa mesma realidade, ou seja, seu questionamento. Sem essa radicalidade, a arte "seria marcada por insignificância e reduzida a puro divertimento" - Adorno diria: reduzida à "indústria cultural". (GAGNEBIN, 2016, p. 13, grifo da autora).

Gagnebin (2016) destaca ainda que a defesa dessa dimensão ontológica da literatura é o que nos permite encarar com um pouco mais de segurança as relações entre ela e a filosofia. Separadas por Platão para permitir a nomeação de outro ideal de discurso, o logos filosófico, elas não precisam permanecer distantes e intocáveis, ou tampouco misturar-se numa fusão completa. Sua separação também persiste por razões históricas ligada à diferenciação histórica das disciplinas, especialmente no contexto do ensino escolar e universitário onde cada uma defende o próprio território. Dentro dessa contextualização histórica pode-se estudar com proveito as chamadas formas literárias da filosofia, indispensáveis ao bom entendimento dos textos filosóficos:

[...] se Platão escreve diálogos (e não elabora um sistema totalizante), é justamente porque ele quer ressaltar que a filosofia é primeiramente um diálogo vivo entre interlocutores benevolentes, uma busca em comum. Se Montaigne inventa o gênero "Ensaios", é porque ele não pode mais edificar uma descrição dedutiva e racional, por ceticismo, claro, e pela natureza do seu objeto, esse "eu" multiforme. Mesmo 
Kant deve desistir da edificação completa de um sistema como o da razão pura quando se trata de compreender as regras da ação moral e as da arte. Depois de Nietzsche, quem de nós ainda ousaria escrever um sistema totalizante? O que não significa que somente os aforismos e os fragmentos por si nos garantem profundidade! . (GAGNEBIN, 2016, p. 13, grifo da autora).

Esse movimento autorreflexivo da filosofia sobre seu caráter de linguagem - sobre sua forma literária - nos permite, portanto, em termos de história da filosofia, uma leitura renovada, mais atenta às singularidades dos textos.

Conclui-se que filosofia e literatura vivem do permanente enigma das relações entre linguagem e mundo. A reflexão sobre suas formas literárias pode auxiliar a filosofia a ampliar a área de clareza que circunda este enigma. Por não ter as mesmas pretensões, talvez a literatura permaneça tranquila diante deste enigma. Isso não significa, contudo, que ela não precise se valer de invenções e figurações sempre renovadas descartando a possibilidade de se aventurar pelos caminhos do conhecimento (GAGNEBIN, 2016).

\section{CONSIDERAÇÕES FINAIS}

Retomando brevemente o que fora exposto, qualquer abordagem metodológica que se pretenda eficaz deve levar em consideração a natureza da disciplina à qual pretende se ajustar. Afinal, embora pertençam à mesma "espécie" enquanto áreas do conhecimento, cada uma possui um modo próprio de lidar com os objetos que são caros à sua investigação. Em se tratando de filosofia, compreendê-la essencialmente como problemática - considerando, a um tempo, o problema como seu elemento constitutivo mais fundamental e como força mobilizadora do pensamento - nos permite unificar todas as concepções desenvolvidas pelos filósofos ao longo de sua história. Ter clareza quanto a isso é fundamental para que se possa desenvolver estratégias metodológicas adequadas, evitando o erro corrente de se atribuir à disciplina tarefas que lhes são naturalmente estranhas.

No Brasil, algumas propostas metodológicas foram desenvolvidas. Dentre elas, a abordagem problemática nos parece a mais adequada. Além de ser coerente com a natureza da disciplina, ela não restringe a aprendizagem da filosofia à assimilação das estruturas internas de um texto ou à apreensão de sua história, mas antes objetiva o exercício do filosofar pelos estudantes: exercício este que parte da experiência real e sensível dos próprios problemas.

No contexto da educação básica, filosofia e outras tantas disciplinas disputam espaço enquanto constituem oficialmente o currículo do ensino médio em muitos estados do país. Considerando sua constituição histórica e linguística e suas antigas e tão íntimas relações com a literatura, apostamos nesse diálogo com vistas à elaboração de uma proposta metodológica para o ensino de filosofia no ensino médio: de modo prático e muito sintético pode-se adotar como ponto de partida para as aulas de filosofia os problemas que mobilizaram o pensamento dos filósofos ao longo da história. Aprende-se, então, como eles lidaram com os próprios problemas e de que maneira esse enfrentamento resultou na criação de conceitos. Posteriormente, aprendese a lidar com os próprios problemas. O combate pessoal com a própria realidade mobiliza nosso pensamento, conduzindo-nos à criação conceitual. Todos esses processos são impensáveis sem a presença da literatura: ela não só viabiliza o acesso aos textos filosóficos, como também materializa o exercício do filosofar. 


\section{REFERÊNCIAS}

BENOIT, Lelita Oliveira. Leitura e a interpretação de textos filosóficos: teorias e experiências. In: CARVALHO, M; CORNELLI, G (Org.). Ensinar filosofia. Vol. 2. Cuiabá: Central de Texto, 2013, cap. 8, p. 131-141.

GAGNEBIN, Jeanne Marie. Filosofia e Literatura. Revista Limiar, Guarulhos, vol. 3, n. 5, 4-14, 2016.

GALLINA, Simone Freitas da Silva. O ensino de filosofia e a criação de conceitos. Cad. Cedes, Campinas, vol.24, n. 64, p.359-371, 2004.

GALLO, Silvio Donizetti de Oliveira. Metodologia do ensino de filosofia: uma didática para o ensino médio. Campinas: Papirus, 2012.

GUIDO, Humberto; GALLO, Silvio Donizetti de Oliveira; KOHAN, Walter Omar. Princípios e possibilidades para uma metodologia filosófica do ensino de filosofia: história, temas, problemas. In: CARVALHO, M; CORNELLI, G (Org.). Ensinar filosofia. Vol. 2. Cuiabá: Central de Texto, 2013, cap. 7, p. 105-128.

HEUSER, Ester Maria Dreher. Modos de ler a filosofia: uma conversa com iniciantes e iniciados. Revista Digital de Ensino de Filosofia. Santa Maria, vol. 2, n.1, p. 6-18, 2016.

MURCHO, Desiderio Orlando Figueiredo. A natureza da filosofia e o seu ensino. Educação, Santa Maria, v.27, n.2, p. 13-17, 2002.

SÃO PAULO (Estado). Secretaria da Educação. Currículo do Estado de São Paulo: Ciências Humanas e suas tecnologias. São Paulo: SEE, 2010. 